\title{
EVALUASI KINERJA PROYEK PEMBANGUNAN RUANG PRAKTIK SISWA (RPS) SMK TERPADU AL-ITTIHAD PURABAYA KABUPATEN SUKABUMI
}

\author{
Nia Kartika dan Adi Chandra Maulana \\ Prodi Teknik Sipil Universitas Muhammadiyah Sukabumi \\ Jl. R. Syamsudin, S.H. No.50 Kota Sukabumi \\ email : niakartika@ummi.ac.id
}

\begin{abstract}
Abstrak
Proyek pembangunan Ruang Praktik Siswa (RPS) SMK Terpadu Al-Ittihad Purabaya Kabupaten Sukabumi yang sedang dilaksanakan mengalami keterlambatan ketika dilihat dari kurva-S antara rencana dan realisasi. Namun, secara rinci keterlambatan itu tidak bisa dirinci berdasarkan kinerja proyek masing-masing ketika hanya melihat dari barchart yang ada. Sehingga pemilik proyek membutuhkan analisis keterlambatannya dan perkiraan biaya dan waktu yang akan dihabiskan ke depannya sampai proyek pembangunannya selesai. Metode analisis pengendalian proyek ini menggunakan metode Earned Value. Informasi yang ditampilkan berupa indikator dalam bentuk kuantitatif, yang menampilkan informasi progres biaya dan jadwal proyek. Hasil penelitian pada akhir peninjauan di minggu ke-8 didapatkan indeks kinerja jadwal (SPI) sebesar 0,91 kurang dari satu dan varian jadwal (SV) bernilai negatif yaitu sebesar -Rp. 11.632.200,yang berarti pelaksanaan proyek lebih lambat dari jadwal yang direncanakan. Nilai indeks kinerja biaya (CPI) sebesar 1,05 lebih dari satu dan nilai varian biaya (CV) bernilai positif sebesar Rp. 5.467.500,- berarti pengeluaran lebih kecil dari anggaran rencana dengan volume yang sama, artinya tidak terjadi kekurangan biaya sampai dengan minggu ke 8. Adapun perkiraan biaya penyelesaian proyek sebesar Rp. 249.831.173,-, dari biaya yang dianggarkan sebesar Rp. 261.416.000,-, sehingga tidak mengalami kerugian. Sedangkan untuk waktu penyelesaian akhir pekerjaan diramalkan selama 15,66 minggu, yang berarti waktu sedikit lebih lambat dari jadwal yang direncanakan selama 15 minggu. Maka perlu adanya peningkatan kinerja di minggu selanjutnya agar proyek dapat selesai sesuai waktu yang direncanakan. Faktor yang mempengaruhi peningkatan kinerja proyek adalah penambahan jam kerja dan tenaga kerja di lapangan, khusunya untuk pekerjaan atap, plafond lantai dan $M E$.
\end{abstract}

Kata Kunci : Pengendalian proyek, Biaya dan Waktu, Earned Value.

\section{PENDAHULUAN}

Pengendalian dalam proyek konstruksi adalah proses pengendalian kinerja proyek yang terdiri dari biaya, waktu, dan sumber daya manusia, material dan peralatan. Sebagaimana proyek pembangunan Ruang Praktik Siswa (RPS) di SMK Terpadu Al-Ittihad Purabaya Kabupaten Sukabumi yang sedang dilaksanakan mengalami keterlambatan ketika dilihat dari kurva-S antara rencana dan realisasi.

Namun, secara rinci keterlambatan itu tidak bisa dirinci berdasarkan kinerja proyek masing-masing ketika hanya meihat dari barchart yang ada. Sehingga pemilik proyek yaitu pihak SMK Al-Ittihad membutuhkan analisis keterlambatannya dan perkiraan biaya dan waktu yang akan dihabiskan ke depannya sampai proyek pembangunannya selesai. Karena dihawatirkan akan mengalami pembengkakan biaya dan keterlambatan waktu, berhubung dengan anggaran yang didapat merupakan hibah dari Pemerintah.

Metode nilai hasil juga dapat digunakan untuk mendeteksi sedini mungkin apabila terjadi adanya pembengkakan biaya maupun keterlambatan yang mungkin terjadi dalam pelaksanaan proyek. Sehingga pihak - pihak yang terkait dalam proyek ini dapat mampu mengatasi suatu kendala - kendala yang bisa mempengaruhi jalannya aktivitas proyek (Gusti Rahma Dini, 2013).

Oleh karena itu, peneliti merasa perlu menganalisis pelaksanaan pembangunan proyek asrama tersebut dengan menggunakan metode Earned Value atau nilai hasil. Informasi yang ditampilkan berupa indikator dalam bentuk kuantitatif, yang menampilkan informasi progres biaya dan jadwal proyek. Indikator ini 
menginformasikan posisi kemajuan proyek dalam jangka waktu tertentu serta dapat memperkirakan proyeksi kemajuan proyek pada periode selanjutnya.

Penelitian ini perlu dilakukan mengingat pelaksanaan pembangunan asrama dilihat dari barchart dari awal mengalami keterlambatan, maka perlu adanya analisis progres kinerja yang dilaksanakan di lapangan serta perlu adanya estimasi penyelesaian waktu ke depannya. Begitu juga dengan estimasi biaya yang akan dihabiskan sampai proyek selesai apakah ada penambahan atau pengurangan. Sehingga bisa menjadi acuan dalam mengendalikan pekerjaan proyek supaya sesuai dengan waktu dan biaya yang ada.

\section{KAJIAN PUSTAKA}

\section{Proyek dan Manajemen Proyek}

Menurut (Husen, 2010) gabungan dari sumber daya seperti manusia, material, peralatan dan modal/biaya yang dihimpun dalam suatu wadah organisasi sementara untuk mencapai sasaran dan tujuan.

Kegiatan proyek dapat diartikan juga sebagai salah satu kegiatan sementara yang berlangsung dalam jangka waktu terbatas, dengan alokasi sumber daya tertentu dan dimaksudkan untuk menghasilkan produk atau deliverable yang kriteria mutunya telah digariskan dengan jelas (Soeharto, 2001).

\section{Kinerja Proyek}

Menurut Cleland, dalam (Mandiyo Priyo, 2017), standar kinerja diperlukan untuk melakukan tindakan pengendalian terhadap penggunaan sumber daya yang ada dalam suatu proyek. Hal ini agar sumber daya dapat dimanfaatkan secara efektif dan efisien dalam penyelenggaraan proyek.

Adapun yang disebut kinerja proyek adalah sebagai berikut :
a. Anggaran Biaya
b. Penjadwalan
c. Mutu

\section{Pengendalian Proyek}

Pengendalian proyek ada 3 macam yaitu : pengendalian biaya proyek, pengendalian waktu/jadwal proyek, dan pengendalian kinerja proyek.

1) Pengendalian Biaya

Menurut (Soeharto, 2001) pengendalian biaya merupakan langkah akhir dari proses pengelolaan biaya proyek, yaitu mengusahakan agar penggunaan dan pengeluaran biaya sesuai dengan perencanaan, berupa anggaran yang telah ditetapkan.

Kemudian ada juga komponen biaya proyek yang perlu dipertimbangkan sebelum proyek selesai dan siap dioprasikan, yaitu modal tetap (fixed capital). Model tetap adalah bagian dari biaya proyek yang dipakai untuk membangun instalasi atau menghasilkan produk proyek yang diinginkan. Modal tetap dibagi menjadi biaya langsung (direct cost) dan biaya tidak langsung (indirect cost).

1. Biaya langsung

Biaya langsung terdiri dari :

a. Penyiapan lahan (Site preparation).

b. Pengadaan peralatan utama.

c. Biaya merakit dan memasang peralatan utama.

d. Alat-alat listrik dan instrumen.

e. Pembangunan gedung perkantoran, pusat pengendalian operasi, gudang, dan bangunan civil lainnya.

f. Pembebasan tanah.

2. Biaya tidak langsung

Biaya tidak langsung meliputi antara lain :

a. Gaji tetap dan tunjangan.

b. Kendaraan dan peralatan konstruksi.

c. Pembanguanan fasilitas sementara.

d. Pengeluaran umum.

e. Laba kontinjensi.

f. Overhead

g. Pajak, pungutan/sumbangan, biaya perijinan, dan asuransi.

2) Pengendalian Waktu/Jadwal

Menurut Soeharto (2001) perencanaan proyek keseluruhan secara garis besar dilaksanakan pada taraf permulaan proyek dan selalu ditinjau ulang ketika perkembangannya tidak sesuai dengan rencana. Penjadwalan adalah pengaturan perincian yang dibutuhkan untuk melaksanakan rencana itu. Dimulai dengan taraf desain, dikembangkan pada waktu pemberian kontrak, kemudian dipakai sebagai dasar pengendalian pada saat pembelian subkontrak diadakan atau sampai konstruksi.

Perencanaan dan penjadwalan bagian dari pentusunan biaya integral. Jadwal itu menunjukan persentase pekerjaan di tempat kerja, pekerjaan untuk diselesaikan, dan urutan pekerjaan itu sendiri. Laporan-laporan status biaya dan jadwal dibuat secara terpadu dan dibawah supervisi manajer yang sama, misalnya manajer kontrol.

3) Pengendalian Kinerja Proyek 
Memantau dan mengendalikan biaya dan waktu secara terpisah tidak dapat menjelaskan proyek pada saat pelaporan. Sebagai contoh dapat terjadi dalam suatu laporan, kegiatan dalam proyek berlangsung lebih cepat dari jadwal/waktu sebagaimana mestinya yang diharapkan, akan tetapi biaya yang dikeluarkan melebihi anggaran. Bila tidak segera dilakukan tindakan pengendalian maka dapat berakibat proyek tidak dapat diselesaikan secara keseluruhan karena pemanfaatan dana alokasi yang kurang optimal. Oleh karena itu, perlu dikembangkan dengan suatu metode yang dapat memberikan suatu kinerja. Salah satu metode yang bisa memenuhi tujuan ini adalah metode Earned

\section{Metode Earned Value}

Konsep Earned Value (nilai hasil) adalah konsep menghitung besarnya biaya yang menurut anggaran sesuai dengan pekerjaan yang telah diselesaikan/dilaksanakan. Metode nilai hasil atau Earned Valuedapat digunakan sebagai tolok ukur kinerja proyek secara terpadu antara biaya dan waktu (Mandiyo Priyo, 2017).

Metode Earned Value atau Nilai Hasil menampilkan indikator dalam bentuk kuantitatif, yang menampilkan informasi progress biaya dan jadwal proyek. Indikator ini menginformasikan posisi kemajuan proyek dalam jangka waktu tertentu serta dalam memperkirakan proyeksi kemajuan proyek pada periode selanjutnya. Indikator-indikator tersebut adalah sebagai berikut :

a. BCWS (Budgeted Cost of Work Shedule), menggambarkan anggaran rencana sampai pada periode tertentu terhadap volume rencana proyek yang akan dikerjakan

b. BCWP (Budgeted Cost of Work Performed), menggambarkan anggaran rencana proyek pada periode tertentu terhadap apa yang telah dikerjakan pada volume pekerjaan aktual

c. ACWP (Actual Cost of Work Performed), menggambarkan anggaran aktual yang dihabiskan untuk pelaksanaan pekerjaan pada keadaan volume pekerjaan aktual

Dengan ketiga indikator tersebut, pengukuran kinerja biaya dan waktu untuk metode Earned Value menggunakan 3 jenis kurva sebagai nilai kumulatif biaya dengan fungsi waktu yang terintegrasi dalam suatu tampilan yang terdiri atas nilai kumulatif biaya BCWS, BCWP dan ACWP.
Kemudian dilakukan analisis terhadap penyimpangan yang terjadi pada biaya dan waktu dengan cara mengukurnya. Analisis terhadap Penyimpangan :

1. Penyimpangan Jadwal/Waktu

a. SV (Sheduling Variance) $=\mathrm{BCWP}-$ BCWS

$\mathrm{SV}>0$, progres aktual $>$ rencana : terjadi percepatan proyek terhadap rencana (shedule underrun)

$\mathrm{SV}<0$, progres aktual $<$ rencana : terjadi keterlambatan proyek terhadap rencana (shedule overrun)

b. SPI (Sheduling Performance Index) = BCWP / BCWS

SPI $>1$, progres aktual $>$ rencana : terjadi percepatan proyek terhadap rencana (shedule underrun)

SPI $<1$, progres aktual $<$ rencana : terjadi keterlambatan proyek terhadap rencana (shedule overrun)

Analisis terhadap Penyimpangan :

2. Penyimpangan Biaya

a. CV $($ Cost Variance $)=\mathrm{BCWP}-\mathrm{ACWS}$

$\mathrm{CV}>0$, biaya volume aktual $>$ biaya aktual (cost underrun)

$\mathrm{CV}<0$, biaya volume aktual $<$ biaya aktual (cost overrun)

b. CPI (Cost Performance Index $)=\mathrm{BCWP} /$ ACWP

CPI $>1$, biaya volume aktual $>$ biaya aktual (cost underrun)

CPI $<1$, biaya volume aktual $<$ biaya aktual (cost overrun)

Dengan menghitung indeks-indeks di atas akan terlihat bahwa proyek akan terlambat atau lebih cepat dan biaya yang harus dikeluarkan akan berlebih atau berkurang dari yang dianggarkan, maka kemajuan proyek untuk waktu yang akan dating perlu diramalkan dengan cara perrkiraan penyelesaian proyek :

1. Perkiraan penyelesaian proyek (estimate completion date) :

$\mathrm{ECD}=($ sisa waktu/SPI $)+$ waktu terpakai

Presentase keterlambatan/percepatan = $100 \%$ - ECD/jadwal rencana x $100 \%$

2. Perkiraan biaya penyelesaian proyek (estimate at completion) :

EAC = sisa anggaran/CPI + ACWP

$=($ total biaya $-\mathrm{BCWP}) / \mathrm{CPI}+$ ACWP 
Presentase biaya penambahan/penurunan biaya aktual terhadap anggaran biaya $=100 \%$-EAC/total biaya $\times 100 \%$

3. Earned Value = BCWPnth

Biaya penyelesaian volume pekerjaan pada periode tertentu

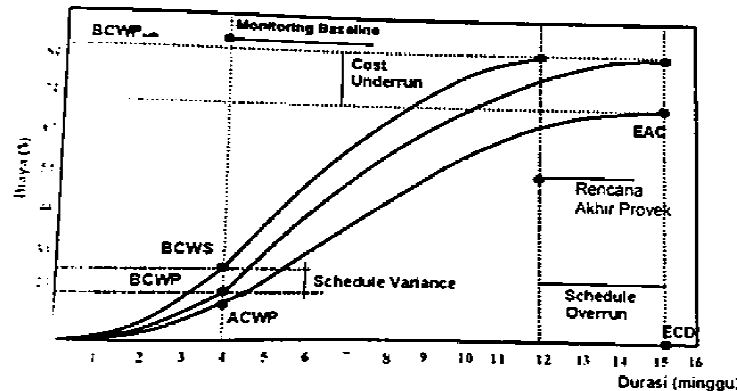

Gambar 1. Grafik kinerja biaya dan waktu kondisi 1 Sumber : (Husen, 2010)

- Pada baseline minggu ke-4 sebagai periode waktu yang diukur kinerjanya terlihat bahwa nilai $\mathrm{BCWP}<\mathrm{BCWS}$, dapat disimpulkan bahwa proyek tersebut mengalami penyimpangan waktu (shedule overrun)

- Untuk periode yang sama $\mathrm{ACWP}<\mathrm{BCWP}$, menunjukkan biaya aktual yang dikeluarkan lebih kecil dari penyelesaian volume pekerjaannya, berarti tidak terjadi penyimpangan biaya (cost underrun)

- Nilai hasil pada minggu ke-4 BCWP nya dibawah BCWS tapi diatas ACWP, di bawah yang seharusnya.

- Pada akhir minggu ke-12, kinerja biaya terus membaik, ACWP $<$ BCWP tetapi $\mathrm{BCWP}<\mathrm{BCWS}$ yang berarti progres waktunya tetap terlambat hingga selesai (shedule overrun).

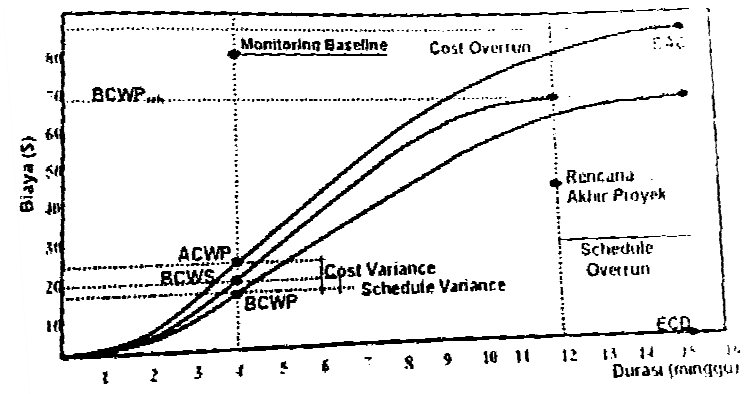

Gamba 2. Grafik kinerja biaya dan waktu kondisi 2 Sumber : (Husen, 2010)

- Pada baseline minggu ke-4 sebagai periode waktu yang diukur kinerjanya terlihat bahwa nilai $\mathrm{BCWP}<\mathrm{BCWS}$, dapat disimpulkan bahwa proyek tersebut mengalami penyimpangan waktu (shedule overrun)
- Untuk periode yang sama ACWP $>B C W P$, menunjukkan biaya aktual yang dikeluarkan lebih besar dari pada penyelesaian volume pekerjaannya, berarti terjadi penyimpangan biaya (cost overrun)

- Nilai hasil pada minggu ke-4 BCWP nya dibawah ACWP dan BCWS, di bawah yang seharusnya

- Pada akhir minggu ke-12, kinerja biaya terus buruk, ACWP $>$ BCWP dan $\mathrm{BCWP}<\mathrm{BCWS}$ yang berarti progres waktunya tetap terlambat hingga selesai (shedule overrun)

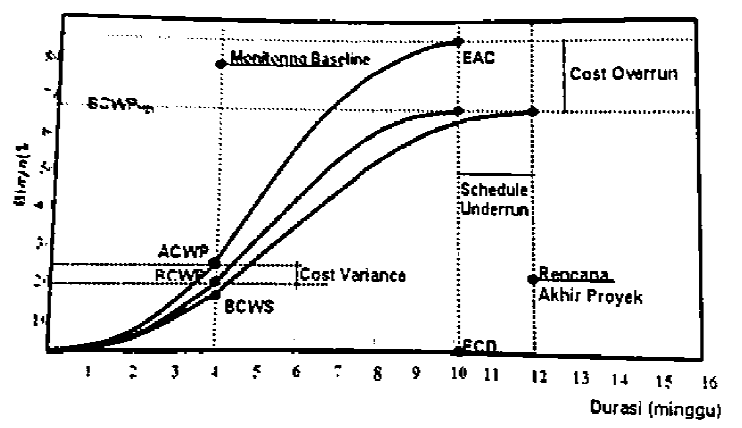

Gambar 3. Grafik kinerja biaya dan waktu kondisi 3 Sumber : (Husen, 2010)

- Pada baseline minggu ke-4 sebagai periode waktu yang diukur kinerjanya terlihat bahwa nilai $\mathrm{BCWP}>\mathrm{BCWS}$, dapat disimpulkan bahwa proyek tersebut mengalami percepatan waktu (shedule underrun)

- Untuk periode yang sama ACWP>BCWP, menunjukkan biaya aktual yang dikeluarkan lebih besar dari pada penyelesaian volume pekerjaannya, berarti terjadi penyimpangan biaya (cost overrun)

- Nilai hasil pada minggu ke-4 BCWP nya diatas BCWS dan di bawah ACWP, di bawah yang seharusnya

- Pada akhir minggu ke-12, ternyata volume penyelesaian melampaui volume rencana, $\mathrm{BCWP}>\mathrm{BCWS}$ yang berarti progres waktunya mengalami percepatan hingga selesai (shedule underrun)

- Nilai ACWP>BCWP menunjukkan biaya aktual lebih besar dari penyelesaian volume pekerjaan (cost overrun) 


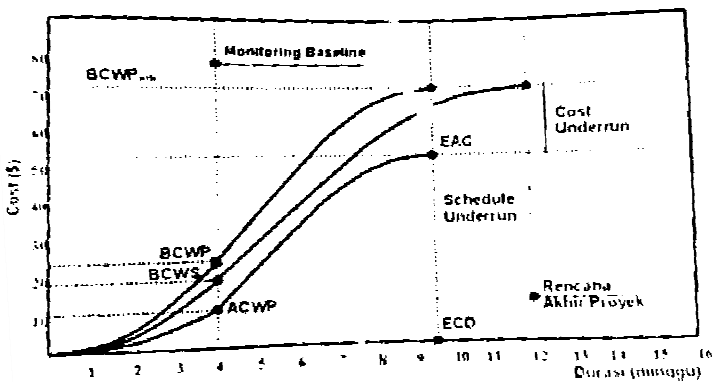

Gambar 4. Grafik kinerja biaya dan waktu kondisi 4 Sumber : (Husen, 2010)

- Pada baseline minggu ke-4 sebagai periode waktu yang diukur kinerjanya terlihat bahwa nilai $\mathrm{BCWP}>\mathrm{BCWS}$, dapat disimpulkan bahwa proyek tersebut mengalami percepatan waktu (shedule underrun)

- Untuk periode yang sama $\mathrm{ACWP}<\mathrm{BCWP}$, menunjukkan biaya aktual yang dikeluarkan lebih kecil dari pada penyelesaian volume pekerjaannya, berarti terjadi penghematan biaya (cost onderrun)

- Nilai hasil pada minggu ke-4 BCWP nya diatas BCWS dan di atas ACWP

- Pada akhir minggu ke-10, ternyata volume penyelesaian melampaui volume rencana, $\mathrm{BCWP}>\mathrm{BCWS}$ yang berarti progres waktunya mengalami percepatan hingga selesai (shedule underrun)

- Nilai ACWP $<$ BCWP menunjukkan biaya aktual lebih kecil dari penyelesaian volume pekerjaan (cost onderrun)

\section{METODE PENELITIAN}

Metode penelitian yang digunakan dalam penelitian ini adalah metode kuantitatif. Data primer diperoleh dari data riil di lapangan berupa realisasi anggaran, laporan progres pekerjaan dan laporan keuangan proyek.

Adapun tahapan penelitiannya secara ringkas digambarkan berikut ini.

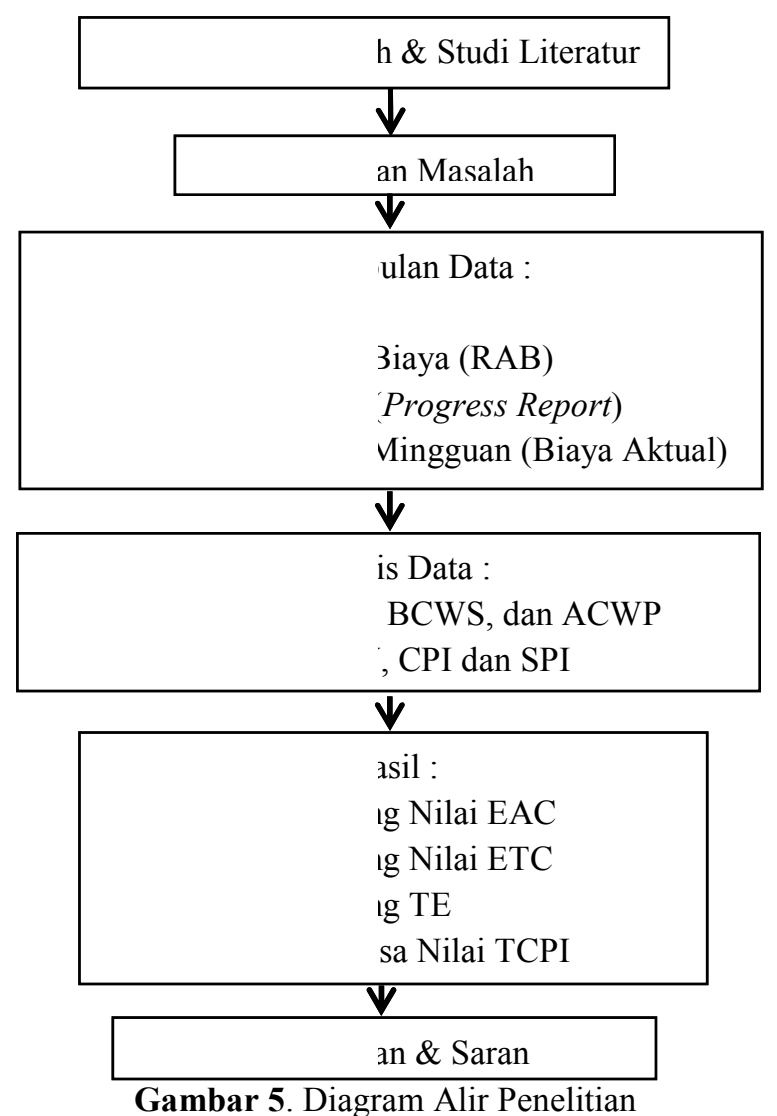

ANALISIS DAN PEMBAHASAN

1. Gambaran Umum Proyek

Gambaran umum dari Proyek

Pembangunan Ruang Praktik Siswa (RPS)

SMK Al-Ittihad Purabaya Kabupaten

Sukabumi adalah sebagai berikut :

Pemilik Proyek : SMK Al-Ittihad

Biaya langsung : Rp. 237.651.361,08

PPN 10\% $\quad$ : Rp. 23.765.136,11

Anggaran Proyek : Rp. 261.416.497,19

Waktu pelaksanaan : 15 minggu

2. Perhitungan Kinerja Proyek

a. Rencana dan Realisasi Pelaksanaan

Pada penelitian ini, evaluasi pekerjaan dilakukan pada minggu ke- 8 dari total rencana 15 minggu, sehingga terdapat sisa waktu kontrak yaitu 7 minggu. 


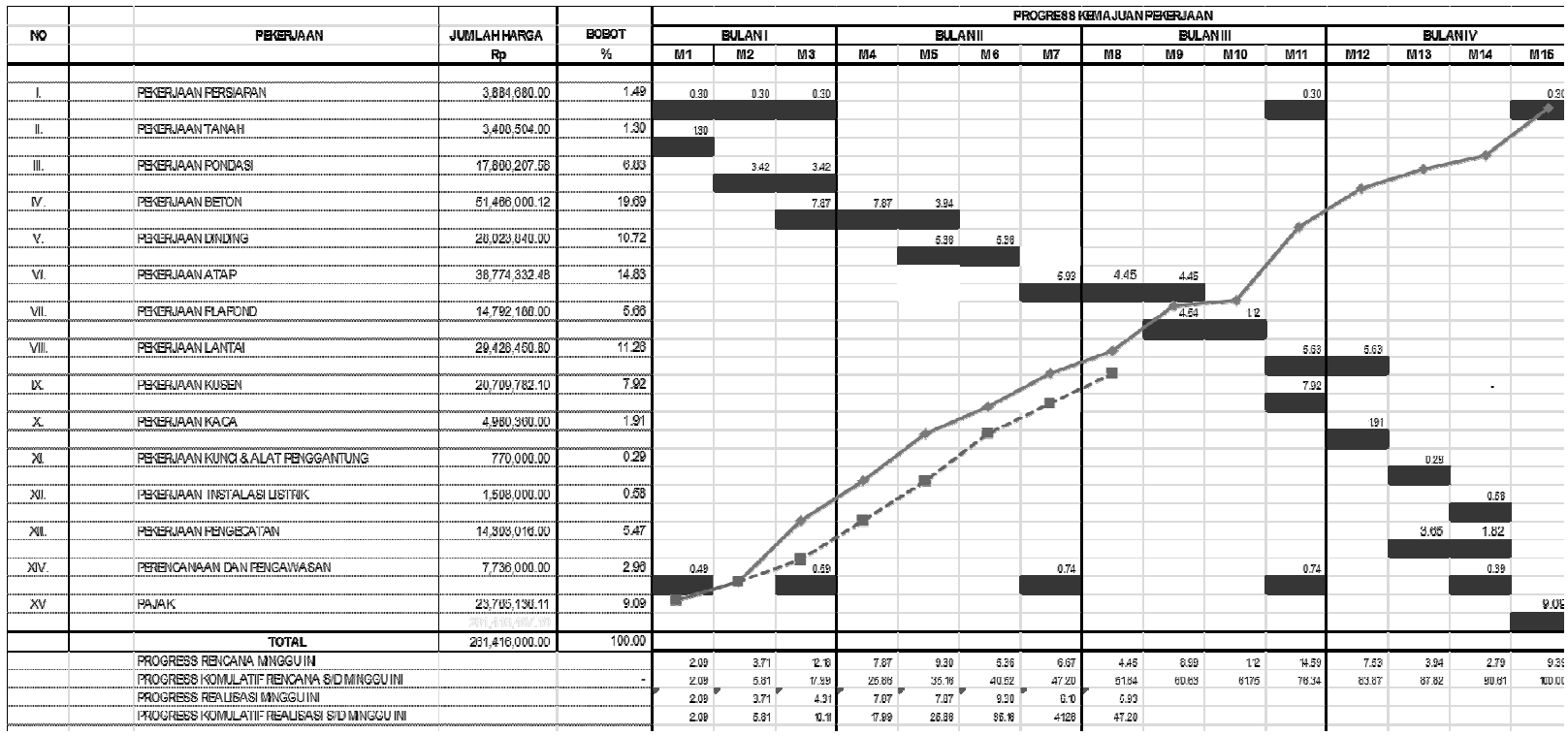

Gambar 6. Kurva-S Rencana dan Realisasi di minggu ke-8

Dari gambar kurva-S rencana dan realisasi dapat dilihat dari minggu ke 1 sampai minggu ke 8 kemajuan proyek di bawah rencana yang artinya waktu lebih lambat dalam pelaksanaannya. Minggu 1 sampai minggu ke 2 terlihat progres sama dengan rencana, namun minggu 3-8 terjadi keterlambatan pekerjaan, sehingga prosentase kemajuan menjadi minus. Secara kumulatif, kurva-S rencana di atas realisasi.

3. Analisis Waktu dan Biaya dengan Metode Earned Value

Kinerja pelaksanaan suatu proyek dapat diukur salah satunya dengan metode nilai hasil (earned value), yaitu biaya yang telah direncanakan terhadap kemajuan pekerjaan yang sedang dilaksanakan. Data yang dibutuhkan untuk mendapatkan kinerja pelaksanaan atau nilai hasil adalah biaya aktual yang telah dikeluarkan untuk pekerjaan yang telah dilaksanakan (ACWP), biaya pekerjaan pada saat pelaporan menurut anggaran (BCWP), dan biaya pekerjaan yang telah dijadwalkan untuk diselesaikan dalam durasi yang telah ditentukan (BCWS). Data yang digunakan dalam penelitian ini adalah biaya yang mulai dikeluarkan di minggu 1 sampai minggu 8 , baik secara aktual, pelaporan, maupun rencana. Dalam tabel dibawah ini data biaya yang disandingkan adalah data biaya secara aktual (realisasi) dengan data biaya rencana pada minggu yang sama.

Tabel 1. Hasil Komulatif Gabungan antara ACWP, BCWP dan BCWS

\begin{tabular}{|c|c|c|c|c|c|}
\hline \multirow{2}{*}{$\begin{array}{c}\text { MINGGU } \\
\text { KE }\end{array}$} & \multirow{2}{*}{$\begin{array}{c}\text { ACWP } \\
\begin{array}{c}\text { KUMULATIF } \\
(\mathbf{R p})\end{array}\end{array}$} & \multirow{2}{*}{$\begin{array}{c}\text { BOBOT } \\
\text { RENCANA } \\
\% \\
\end{array}$} & \multirow{2}{*}{$\begin{array}{c}\text { BCWS } \\
\begin{array}{c}\text { KUMULATIF } \\
(\text { Rp) }\end{array} \\
\end{array}$} & \multirow{2}{*}{$\begin{array}{c}\text { BOBOT } \\
\text { RENCANA } \\
\% \\
\end{array}$} & \multirow{2}{*}{$\begin{array}{c}\text { BCWP } \\
\text { KUULATIF } \\
\text { (Rp) } \\
\end{array}$} \\
\hline & & & & & \\
\hline 1 & 00 & 371 & 00 & 87 & 5,47 \\
\hline 2 & 14,61 & 12.18 & .00 & 7.87 & 15,184 \\
\hline 3 & 26,66 & 787 & 47,0 & 9.30 & 26,442 \\
\hline 4 & $51,250,4$ & 9.30 & 67,615 , & 6.10 & $47,028,700$. \\
\hline 5 & $68,117,700.00$ & 5.36 & $91,920,300.00$ & 5.93 & $67,615,200.0$ \\
\hline
\end{tabular}




\begin{tabular}{rrrrrr}
\hline 6 & $93,733,800.00$ & 6.67 & $105,932,300.00$ & - & $91,920,400.00$ \\
\hline 7 & $108,084,800.00$ & 4.45 & $123,376,100.00$ & $-107,866,400.00$ \\
\hline 8 & $117,908,700.00$ & 8.99 & $135,008,400.00$ & $-123,376,200.00$ \\
\hline
\end{tabular}

Berdasarkan tabel diatas, maka pengamatan pada minggu ke 8 didapat nilai berikut:
a). BCWS
$=$ Rp. 135.008.400,-
b). BCWP
$=$ Rp. 123.376.200,-
c). ACWP
$=$ Rp. 117.908.700,-
d). SPI
$=\mathrm{BCWP} / \mathrm{BCWS}$
$=$ Rp. 123.376.200/
Rp. 135.008 .400
e). CPI
$=0,91$
$=\mathrm{BCWP} / \mathrm{ACWP}$
$=$ Rp. 123.376.200/
Rp. 117.908 .700

$=1,05$

f). SV

$=$ BCWP-BCWS

$=$ Rp. 123.376.200-

Rp. 135.008 .400

$=-$ Rp. 11.632.200,-

g). $\mathrm{CV}$

$=$ BCWP-ACWP

$=$ Rp. 123.376.200-

Rp. 117.908 .700

$=$ Rp. 5.467.500,-

h). ETC

$=($ Total $-\mathrm{BCWP}) / \mathrm{CPI}$

$=($ Rp. 261.416.000-

Rp.123.376.200)

$/ 1,05$

$=$ Rp. 131.922.473,-

i). ETS

$=($ Rencana WaktuWaktu Pengamatan) /SPI

$=(15-8) / 0,91$

$=7,66$ minggu

j). EAC

$=\mathrm{ETC}+\mathrm{ACWP}$

$=$ Rp. 131.922.473+

Rp. 117.908.700,-

$=$ Rp. 249.831.173,-

k). ECD

$=$ ETS +Waktu

Pengamatan

$=7,66+8$

$=15,66$

1). Rencana biaya total proyek

$=$ Rp. 261.416.000,-

EAC

$=$ Rp. 249.831.173,-

Selisih biaya $=$ Rp. 11.584.827,-

Dari hasil perhitungan di atas, maka dianalisis nilai hasilnya sesuai dengan persyaratan yang ada, menghasilkan data sebagai berikut :

- Analisis Penyimpangan Jadwal/Waktu a. SPI (Sheduling Performance Index) $=0,91$

SPI $<1$, progres aktual $<$ rencana : maka terjadi keterlambatan proyek terhadap rencana (shedule overrun)

b. SV (Sheduling Variance) $=-\mathrm{Rp}$. 11.632.200,-

$\mathrm{SV}<0$, progres aktual $<$ rencana : terjadi keterlambatan proyek terhadap rencana (shedule overrun)

- Analisis Penyimpangan Biaya

a. CPI (Cost Performance Index) = 1,05

CPI $>1$, biaya volume aktual $>$ biaya aktual (cost underrun)

b. $\mathrm{CV}$ (Cost Variance) $=\mathrm{Rp}$. 5.467.500,-

$\mathrm{CV}>0$, biaya volume aktual $>$ biaya aktual (cost underrun)

- Perkiraan penyelesaian proyek:

ECD (Estimate Completion Date) = 15,66 minggu

- Perkiraan biaya penyelesaian proyek :

EAC (Estimate At Completion) $=\mathrm{Rp}$. 249.831.173,-

Perbandingan biaya pekerjaan sesuai anggaran (BCWS), biaya pekerjaan pelaporan menurut anggaran (BCWP), biaya aktual pekerjaan (ACWP) dapat dilihat pada gambar di bawah ini.

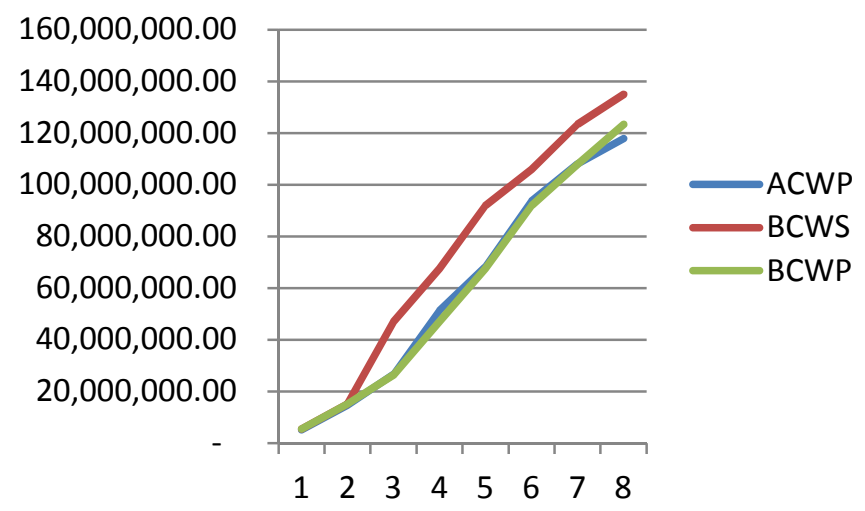


Gambar 7. Kurva Perbandingan ACWP, BCWS, BCWP

Berdasarkan gambar diatas terlihat bahwa biaya pekerjaan sesuai anggaran (BCWS) berjauhan dan ada diatas dari biaya pelaporan sesuai anggaran (BCWP) dan BCWP berimpitan dengan biaya aktual (ACWP) yang berarti realisasi biaya pelaksanaan lebih kecil dari biaya sesuai pelaporan. Perbandingan antara indeks kinerja biaya (CPI) dan indeks kinerja jadwal (SPI) dihitung berdasarkan konsep nilai hasil secara menyeluruh dari minggu 1 sampai minggu 8 dapat dilihat pada tabel dibawah ini :

Tabel 2. Komulatif Bobot Minggu ke 1 sampai minggu ke 8 (dalam rupiah)

\begin{tabular}{ccccccccc}
\hline $\begin{array}{c}\text { MINGGU } \\
\text { KE }\end{array}$ & ACWP & BCWS & BCWP & SV & CV & SPI & CPI \\
\hline 1 & $5,192,700 .-$ & $5,474,800 . \cdot$ & $5,474,800 .-$ & & - & $282,100 .-$ & 1.00 & 1.05 \\
\hline 2 & $14,613,700 .-$ & $15,184,900 . \cdot$ & $15,184,900 .-$ & & - & $571,200 .-$ & 1.00 & 1.04 \\
\hline 3 & $26,660,800 .-$ & $47,028,600 . \cdot$ & $26,442,200 .-$ & $(20,586,400 .-)$ & $(218,600 .-)$ & 0.56 & 0.99 \\
\hline 4 & $51,250,400 .-$ & $67,615,100 . \cdot$ & $47,028,700 .-$ & $(20,586,400 .-)$ & $(4,221,700 .-)$ & 0.70 & 0.92 \\
\hline 5 & $68,117,700 .-$ & $91,920,300 . \cdot$ & $67,615,200 .-$ & $(24,305,100 .-)$ & $(502,500 .-)$ & 0.74 & 0.99 \\
\hline 6 & $93,733,800 .-$ & $105,932,300 . \cdot$ & $91,920,400 .-$ & $(14,011,900 .-)$ & $(1,813,400 .-)$ & 0.87 & 0.98 \\
\hline 7 & $108,084,800,-$ & $123,376,100 . \cdot 107,866,400 .-$ & $(15,509,700 .-)$ & $(218,400 .-)$ & 0.87 & 1.00 \\
\hline 8 & $117,908,700 .-$ & $135,008,400 . \cdot 123,376,200 .-$ & $(11,632,200 .-)$ & $5,467,500 .-$ & 0.91 & 1.05 \\
\hline
\end{tabular}

Dari tabel diatas dapat dilihat bahwa prestasi pelaksana dalam pekerjaan ini kurang baik. Angka SPI dari minggu pertama sampai minggu ke delapan mayoritas dibawah 1 yang berarti pekerjaan lebih lambat dari jadwal walaupun memang deviasinya sangat kecil, bahkan di minggu 8 mengalami kenaikan hamper mendekati 1 artinya hampir sesuai dengan perencanaan. Sedangkan CPI setengahnya kurang dari satu dan setengahnya lebih dari satu yang berarti secara pembiayaan tidak mengalami kerugian di lapangan.

\section{KESIMPULAN}

Hasil penelitian evaluasi kinerja proyek Ruang Praktik Siswa (RPS) SMK Al-Ittihad Purabaya Kabupaten Sukabumi menggunakan metode Nilai Hasil dihasilkan beberapa hal berikut :

1. Pada akhir peninjauan (minggu ke-8), untuk Indeks kinerja jadwal (SPI) sebesar 0,91 kurang dari satu yang berarti pelaksanaan proyek lebih lambat dari jadwal yang direncanakan. Nilai indeks kinerja biaya (CPI) sebesar 1,05 lebih dari satu berarti pengeluaran lebih kecil dari anggaran rencana dengan volume yang sama, artinya tidak terjadi kekurangan biaya sampai dengan minggu ke 8 .

2. Varian jadwal (SV) bernilai negatif yaitu sebesar -Rp. 11.632.200,- berarti proyek mengalami keterlambatan, karena ada perbedaan antara biaya yang seharusnya dikeluarkan tidak sesuai dengan prestasi pekerjaan yang telah dijadwalkan dan perbedaannya disini bernilai negatif. Sedangkan nilai varian biaya $(\mathrm{CV})$ bernilai positif sebesar Rp. 5.467.500,- berarti proyek tidak mengalami kerugian, karena perbedaan antara biaya yang seharusnya dikeluarkan sesuai dengan prestasi pekerjaan dengan biaya yang telah dikeluarkan bernilai positif.

3. Apabila kecenderungan kinerja proyek seperti pada akhir peninjauan di minggu ke-8, maka dapat diperkirakan biaya 
penyelesaian proyek sebesar Rp. 249.831.173,-, dan nilai tersebut diatas biaya yang dianggarkan sebesar Rp. 261.416.000,-. Sedangkan untuk waktu penyelesaian akhir pekerjaan diramalkan selama 15,66 minggu, yang berarti waktu sedikit lebih lambat dari jadwal yang direncanakan selama 15 minggu.

4. Melihat dari hasil analisis kinerja proyek sampai dengan minggu ke-8, maka perlu adanya peningkatan kinerja di minggu selanjutnya agar proyek dapat selesai sesuai waktu yang direncanakan. Faktor yang mempengaruhi peningkatan kinerja proyek adalah penambahan jam kerja dan penambahan tenaga kerja di lapangan. Khusunya untuk pekerjaan atap, plafond dan lantai dan ME. Penambahan tenaga kerja akan berdampak pada peningkatan biaya langsung proyek, namun jika dilihat dari hasil analisis bahwa ada dari sisi biaya tidak mengalami kerugian bahkan diprediksi akan ada kelebihan, maka sebaiknya kelebihan itu digunakan untuk penambahan tenaga kerja sehingga bisa mempersingkat waktu dan bisa menyelesaikan waktu sesuai yang direncanakan yaitu 15 minggu tanpa mengalami kerugian dari sisi biaya juga.

\section{SARAN}

1. Untuk pelaksana pembangunan Ruang Praktik Siswa (RPS) SMK Al-Ittihad Purabaya Kabupaten Sukabumi diharapkan mengendalikan sisa waktu penyelesaian proyek sampai minggu ke-15 dengan meningkatkan kinerja dan mempersingkat waktu, supaya penyelesaian proyek bisa seuai dengan waktu yang tertulis di kontrak agar tidak dikenakan denda atas keterlambatan.

2. Penelitian lebih lanjut perlu dilakukan lebih spesifik tentang metode pengendalian kinerja proyek menggunakan crashing program yang basis datanya berasal dari CPM, sehingga bisa terlihat dalam minggu ke berapa dan dalam pekerjaan apa harus menambah tenaga kerja dan bisa dihitung nilai penambahan biaya proyeknya.

\section{DAFTAR PUSTAKA}

Ervianto, W. 2005. Manajemen Proyek Konstruksi. Yogyakarta : Andi.
Gray,C.F dan E.W,Larson. 2007. Manajemen Proyek, Proses Manajerial. Andi : Yogyakarta.

Gusti Rahma Dini, I. J. 2013. Pengendalian Proyek Pembangunan Lanjutan SMA Negeri Internasional Sumatera Selatan Palembang dengan Metode Earned Value. Jurnal Teknik Sipil dan Lingkungan ISSN: 2355-374X, Vol. 1, No. 1.

Hardianto, A. 2015. Analisa Pengendalian Manajemen Waktu dan Biaya Proyek Pembangunan Hotel dengan Network $C P M$. Jurnal Teknik Sipil Univeritas Muhammadiyah Surakarta, 3-17.

Husen, A. 2010. Manajemen Proyek. Yogyakarta : Penerbit Andi.

Junaidi. 2012. Pengendalian Waktu dan Biaya Pada Tahap Pelaksanaan Proyek dengan Menggunakan Metode Nilai Hasil. Jurnal Sipil Statik. Vol. 1, Nomor 1.

Mandiyo Priyo, T. Z. 2017. Penerapan Metode "Earn Value" dan "Project Crashing" Pada Proyek Konstruksi : Studi Kasus Pembangunan Gedung IGD RSUD Sunan Kalijaga, Demak. Jurnal Ilmiah Semesta Teknika, Vol. 20, No. 1, 29-50.

Soeharto, I. 2001. Manajemen Proyek Dari Konseptual Sampai Operasional Jilid2. Jakarta : Erlangga. 